\title{
Curriculum vitae: Rob Bentley
}

The cranio-oral and maxillofacial surgeon is proud of his work in gaining a helipad at King's College London's major trauma centre.

\section{Humble beginnings}

I was born in Cardiff Royal Infirmary, a hospital I would later work in, and I grew up in Grangetown, the docks area of Cardiff. I was the first person in my family to do A levels. My father left school when he was 11, and my mother when she was 14 . I had an older brother who took up an apprenticeship after his $\mathrm{O}$ levels and I had to work off my own back to find out about higher education, something I like to help tackle now by teaching at careers days in less privileged schools.

\section{Dentistry}

I wanted to do a degree that would lead to a vocational job, so either dentistry or medicine seemed like a good choice. The training seemed to be shorter in dentistry and salaries and hours were reasonably good, so I thought, "That's for me." It was in my last year at the University of Wales College of Medicine that I came across oral and maxillofacial surgery. I remember being in an outpatient clinic, seeing patients coming through the door with such a range of different conditions, from head and neck cancer through to major facial trauma and facial deformity, and I thought, "I want to do this."

\section{Mature student}

After qualifying in dentistry, I worked in hospital posts for 3 years, sat fellowship exams, and went back to medical school in Cardiff for four years. It was a good time but really tough as I had support myself through the second degree by working evenings, weekends, and holidays.

\section{Craniofacial surgery}

In 1987, at the end of my first week working at Birmingham Children's Hospital, I assisted in a baby having its head rearranged for a condition called craniosynostosis. I thought this was the most amazing thing I had ever seen and I knew at that point that I wanted to be a craniofacial surgeon. It's complex and challenging work, which appealed to me, and there is also a strong multidisciplinary element.

\section{Germany}

I did a fellowship in cleft lip and palate in Leipzig, in the former East Germany. That was really interesting because the wall had only been down for six years. They had centralisation of services under the former German Democratic Republic so all the children were treated through one centre in Leipzig. I learnt
German and was employed as a registrar, and I made some great friends, one of whom is now a consultant colleague.

\section{Valuable experience}

In 2000, I spent six months as a craniofacial fellow at the University of Heidelberg. The experience taught me a lot about clinical coding and commissioning, something that I was later involved with as a clinical director for London trauma rehabilitation. In Germany, healthcare was much better funded and the quality of patient experience was better. However, in terms of value for money and efficiency, the NHS at that time was in advance of Germany, through necessity.

\section{Helipad}

In 2010, I became clinical director of the South East London Trauma Network and for King's College Hospital Major Trauma Centre, for 2.5 million people. I worked with commissioners in Medway to ensure that their two million patients could also have access to King's major trauma centre and we went live as the South East London, Kent and Medway Trauma Network (SELKaM) in 2013. At that time, air ambulances had to land in a local park and then the patient had a 25 minute ambulance journey. I led the team in designing, getting the planning permission, and raising money for a helipad at King's. It opened in October 2016 and it means that patients can fly from Margate to King's in 25 minutes. It has greatly improved access to trauma care and I am very proud of that.

\section{Television appearances}

I featured in the Channel 4 programme 24 Hours in $A \& E$ and was embarrassed when they decided to use my voice saying "unconditional love" and "love is a reflex" for the opening sequence of the series. I provide a large cranial reconstruction service and one of my patients featured in a BBC Horizon programme called Richard's War. It's an incredible story. 


\section{Career timeline}

2013-to date: Clinical director of South East London, Kent, and Medway Major Trauma Network

2012-13: London clinical director for trauma rehabilitation

2010-12: Next generation chief executive programme, Healthcare for London and London Business School

2008-17: Clinical director, King's Major Trauma Centre

2008-12: Member of the steering committee for the redesign of the London major trauma system

2000-present: Consultant in oral and maxillofacial surgery, King's College Hospital, London

2000: Trauma attachment, University of Basel, Switzerland

2000: Fellowship in craniofacial surgery, University of Heidelberg, Germany

1999: Fellowship in craniofacial surgery, Birmingham Children's Hospital 1997-98: Fellowship in cleft lip and palate, University of Leipzig, Germany 1994-2000: Specialist registrar rotation in oral and maxillofacial surgery, Birmingham and the West Midlands

1988-92: Medical degree, University of Wales College of Medicine

1981-85: Dentistry degree, University of Wales College of Medicine 